University of Wollongong

Research Online

Australian Institute for Innovative Materials -

Papers

Australian Institute for Innovative Materials

$1-1-2013$

\title{
Preparation and characterisation of graphene composite hydrogels
}

Nicholas J. Whiteside

University of Wollongong

Gordon G. Wallace

University of Wollongong, gwallace@uow.edu.au

Marc in het Panhuis

University of Wollongong, panhuis@uow.edu.au

Follow this and additional works at: https://ro.uow.edu.au/aiimpapers

Part of the Engineering Commons, and the Physical Sciences and Mathematics Commons

Research Online is the open access institutional repository for the University of Wollongong. For further information contact the UOW Library: research-pubs@uow.edu.au 


\title{
Preparation and characterisation of graphene composite hydrogels
}

\begin{abstract}
Stable dispersions containing graphene and gellan gum are used to form composite films. Incorporation of graphene into the gellan gum matrix results in mechanical reinforcement and electrical conductivity at low and high graphene loading fractions, respectively. Graphene-containing gellan gum hydrogel films are prepared by immersion of composite films in $\mathrm{Ca} 2+$ cross-linking solutions. The resulting hydrogels are electrically conducting and exhibit reinforcement compared to the corresponding gellan gum hydrogels. 2013 Elsevier B.V.
\end{abstract}

\section{Keywords}

characterisation, preparation, graphene, hydrogels, composite

Disciplines

Engineering | Physical Sciences and Mathematics

\section{Publication Details}

Whiteside, N. J., Wallace, G. G. \& in het Panhuis, P. H. (2013). Preparation and characterisation of graphene composite hydrogels. Synthetic Metals, 168 (1), 36-42. 


\title{
Preparation and characterisation of graphene composite hydrogels
}

\author{
Nicholas J. Whiteside ${ }^{\mathrm{a}, \mathrm{b}}$, Gordon G. Wallace ${ }^{\mathrm{b}}$, and Marc in het Panhuis ${ }^{\mathrm{a}, \mathrm{b}, *}$ \\ ${ }^{a}$ Soft Materials Group, School of Chemistry, University of Wollongong, Wollongong, NSW 2522, \\ Australia. \\ ${ }^{b}$ Intelligent Polymer Research Institute, ARC Centre of Excellence for Electromaterials Science, \\ AIIM Facility, University of Wollongong, Wollongong, NSW 2522, Australia.
}

* Corresponding author contact details:

E-mail:panhuis@uow.edu.au

Telephone: +61242213155

Keywords: graphene; gellan gum; hydrogels; films; conductivity; composites; mechanical

\begin{abstract}
Stable dispersions containing graphene and gellan gum are used to form composite films. Incorporation of graphene into the gellan gum matrix results in mechanical reinforcement and electrical conductivity at low and high graphene loading fractions, respectively. Graphenecontaining gellan gum hydrogel films are prepared by immersion of composite films in $\mathrm{Ca}^{2+}$ cross-linking solutions. The resulting hydrogels are electrically conducting and exhibit reinforcement compared to the corresponding gellan gum hydrogels.
\end{abstract}

\section{Introduction}

Graphene, in its purest form, exists as a single $2 \mathrm{D}$ monolayer of $\mathrm{sp}^{2}$ carbon atoms in a hexagonally arranged crystal lattice. Within the graphene network, the carbon-carbon sigma bonds are one of the strongest observed within nature, giving rise to their exceptional properties and a significant interest amongst the scientific community. Its separation as a single-monolayer, however, has only recently been examined in $2004^{[1]}$, despite its role as the constituent material of carbon nanotubes (CNTs) and buckministerfullerene. Defect-free graphene sheets possess an array of remarkable thermal, electrical and mechanical properties, 
comparable to those of CNTs ${ }^{[2]}$. Graphene can be produced using, mechanical cleavage of highly ordered, pyrolytic graphite crystals ${ }^{[3]}$, epitaxial growth using chemical vapour deposition (CVD) on silicon carbide ${ }^{[4]}$, through thermally expanded graphite with relatively ${\text { good } \text { yield }^{[5]} \text {, and through electrochemical reduction of graphite oxide }}^{[6]}$. A more practical approach utilises the chemical reduction of exfoliated graphite oxide (GO) sheets to form isolated chemically converted graphene $(\mathrm{CCG})$, which can be prepared in organic and aqueous solvents in good yield ${ }^{[7,8]}$. These dispersions are desirable, as they can be readily processed using solution based techniques to prepare composite materials ${ }^{[9,10,11]}$. Graphene hydrogel films are a new class of materials which are being developed for applications such as electrodes and capacitors ${ }^{[12,13,14,15,16,17]}$.

Gellan gum $(\mathrm{GG})$ is a high molecular weight, linear anionic extracellular polysaccharide secreted by the bacterium Sphingomonas elodea (ATCC 31461) ${ }^{[18]}$. Structurally, it is built up of tetrasaccharide repeat units containing $\beta$-D-glucose, $\beta$-D-glucoronic acid and $\alpha$-Lrhamnose monomers. The natural form is partially acetylated with L-glycerate and $O$-acetate groups substituted on one glucose residue ${ }^{[19]}$. In aqueous environments at elevated temperatures, the polysaccharide exists in a random coil conformation. Cooling below a critical transition temperature promotes a thermally-reversible conformational change to ordered double-helices. The formation of this double-helix is believed to be stabilised through internal hydrogen bonding between the hydroxy methyl groups of 4-linked Dglucosyl units and adjacent hemiacetal oxygen of the L-glycerate on adjacent chains ${ }^{[20]}$. This conformational transition has been characterised by a vast array of techniques including rheometry ${ }^{[21]}$, differential scanning calorimetry ${ }^{[22]}$, nuclear magnetic resonance spectroscopy $^{[23]}$, circular dichroism ${ }^{[24]}$, and more recently by atomic force microscopy ${ }^{[25]}$. The temperature at which this transition occurs has been found to be within the biologically 
relevant region of $\sim 30{ }^{\circ} \mathrm{C}$, and is shifted considerably depending upon variations in the polymer molecular weight ${ }^{[26]}, \mathrm{pH}^{[27]}$, and particularly the presence of cationic species such as $\mathrm{Na}^{+}, \mathrm{K}^{+}, \mathrm{Ca}^{2+}$ and $\mathrm{Mg}^{2+}{ }^{[28]}$.

Further to this conformational change, a more permanent change is induced through a temperature-dependant, cation-induced gelation. Upon cooling below the transition temperature in the presence of sufficient monovalent $\left(\mathrm{K}^{+}\right.$or $\left.\mathrm{Na}^{+}\right)$or divalent cations $\left(\mathrm{Ca}^{2+}\right.$ or $\mathrm{Mg}^{2+}$ ), gel junction zones are formed ${ }^{[29]}$. The aggregation of double helices as a result of charge screening and bridging between carboxyl groups on neighbouring chains. This transition establishes multiple junction zones between surrounding double helices, forming a three-dimensional network, and bridging the polysaccharide backbone ${ }^{[30]}$.

GG has been approved in the US (FDA) and in the EU for food and medical usage as a gelling, stabilizing, and suspending agent ${ }^{[31]}$. It is commonly used within foods such as dessert gels, icings, puddings and glazes ${ }^{[32]}$ and its ideal film forming properties led to its use in coatings and preservation of fruits ${ }^{[33]}$. GG's unique dispersing ability has been utilized in the processing of carbon nanotubes by film casting ${ }^{[34,35,36,37]}$, vacuum filtration ${ }^{[38]}$, inkjet printing $^{[39]}$ and extrusion printing ${ }^{[40]}$.

In this paper, graphene dispersions added to a gellan gum solution have been used to prepare graphene-containing films and hydrogels. We show that the presence of graphene can provide mechanical reinforcement in the films and hydrogels. It is demonstrated that incorporation of graphene in the films results in electrical percolation. 


\section{Experimental methods}

\section{Preparation of solutions and dispersions.}

Solutions of gellan gum (GG) were prepared by adding the appropriate mass of gellan powder (Gelzan CM, CP Kelco, Lot \#9A5250A) to $100 \mathrm{~mL}$ of Milli-Q (MQ) water (Millipore, resistivity $18.2 \mathrm{M} \Omega \mathrm{cm}$ ) under mechanical stirring for $90 \mathrm{~min}$ at $80{ }^{\circ} \mathrm{C}$.

Graphene (CCG) dispersions were prepared by hydrazine reduction of a graphite oxide (GO) precursor. The GO was produced through oxidation/exfoliation of natural graphite powder (SP-1, Bay Carbon) via the modified Hummer's method ${ }^{[41,42]}$. The reduction of GO to CCG was carried out as follows. An appropriate mass of GO precursor material was added to a $1 \mathrm{~L}$ vessel, diluted with MQ water, followed by addition of $1 \mathrm{~mL}$ hydrazine $(35 \% \mathrm{w} / \mathrm{v}$ in water, Aldrich) and $7 \mathrm{~mL}$ of ammonia solution $(28 \% \mathrm{w} / \mathrm{v}$ in water, Crown Scientific) to create a $0.05 \% \mathrm{w} / \mathrm{v}$ dispersion of GO sheets. The resulting homogeneous GO dispersion was then vigorously shaken for a few minutes and the vessel was placed in a water bath and maintained at $95{ }^{\circ} \mathrm{C}$ for 1 hour, yielding a colloidal dispersion $(\mathrm{CCG}, 0.05 \% \mathrm{w} / \mathrm{v})$.

Composite dispersions were prepared by adding the required volume of CCG to a heated (50 $\left.{ }^{\circ} \mathrm{C}\right)$ gellan gum solution. The dispersions were stirred for 10 minutes with heating $\left(40{ }^{\circ} \mathrm{C}\right)$ and then centrifuged $(2000 \mathrm{rpm}, 15 \mathrm{~s})$ to remove entrapped air. The resulting GG-CCG dispersions were prepared such that the CCG concentration was between 0.0025 and $0.045 \%$ w/v with a GG concentration of $1 \% \mathrm{w} / \mathrm{v}$.

\section{Dispersion characterisation}

The homogeneity of the CCG dispersions was assessed by optical microscopy. Specifically, a small volume of the dispersion was placed onto a glass microscope slide and covered with a 
cover slip to ensure appropriate imaging thickness, and to prevent drying. Images of the dispersions were obtained with an optical microscope (Leica Z16 APO).

The zeta potential of $\mathrm{CCG}$ dispersions as a function of $\mathrm{pH}$ and $\mathrm{Ca}^{2+}$ ion concentration was obtained using a zetasizer (ZetaSizer Nano ZS, Malvern Inc). Measurement of the zetapotential as a function of $\mathrm{pH}$ change was performed by preparing $10 \mathrm{~mL}$ dispersions of $10 \mathrm{x}$ diluted $\mathrm{CCG}$, followed by the addition of an appropriate volume of $0.1 \mathrm{M} \mathrm{HCl}$ (from $37 \% \mathrm{AR}$ Grade, Aldrich) to obtain a range of dispersion $\mathrm{pH}$ from approximately 6 to 11 . In a similar manner, the measurement of zeta-potential as a function of added $\mathrm{Ca}^{2+}$ ions was made by preparing $10 \mathrm{~mL}$ dispersions of $10 \mathrm{x}$ diluted $\mathrm{CCG}$ with a small-volume addition of $0.5 \mathrm{M}$ $\mathrm{CaCl}_{2}$ (from $\mathrm{CaCl}_{2} \cdot 2 \mathrm{H}_{2} \mathrm{O}$ salt, Aldrich) to achieve $\mathrm{Ca}^{2+}$ concentrations up to $100 \mathrm{mM}$. The solutions were homogenised by inverting, before pipetting into a clean disposable zeta cuvette (DTS1060C). Three measurements were accumulated for each representative sample composition and the mean and standard deviation determined.

\section{Preparation of hydrogels}

GG-CCG dispersions $\left(60^{\circ} \mathrm{C}\right)$ were stirred whilst the required volume of hot $\left(60{ }^{\circ} \mathrm{C}\right) 1 \mathrm{M}$ $\mathrm{CaCl}_{2}$ was added such that the $\mathrm{Ca}^{2+}$ concentration in solutions was varied between $5 \mathrm{mM}$ and $20 \mathrm{mM}$, followed by stirring for another $5 \mathrm{~min}$. The dispersions were then cooled below the gelation temperature $\left(30^{\circ} \mathrm{C}\right)$.

\section{Preparation of films and hydrogels films}

GG and composite GG-CCG dispersions were prepared, and stirred under moderate heat for 5 minutes to homogenise. The hot dispersions were transferred into polystyrene petri dishes (diameters $\sim 5.5 \mathrm{~cm}$ or $12 \mathrm{~cm}$ ) and dried in a convection oven $\left(40{ }^{\circ} \mathrm{C}\right)$ for 24 hours. After 
drying, the films were peeled off the substrate to yield free-standing films which were stored under controlled ambient conditions $\left(21{ }^{\circ} \mathrm{C}, 45 \% \mathrm{RH}\right)$. The films were then hydrated and cross-linked by immersion for up 180 minutes in $\mathrm{CaCl}_{2}$ solution, followed by rinsing with Milli-Q water (to remove excess ions), and blotting between filter paper to remove excess water. The water content of these films was determined (WC) was calculated using, $\mathrm{WC}=\left(\mathrm{m}_{\mathrm{w}}-\mathrm{m}_{\mathrm{i}}\right) / \mathrm{m}_{\mathrm{w}}$, (Equation 1)

where $m_{i}$ and $m_{w}$ are the initial mass and the mass of the hydrated film at different time points. Measurements of the mass of the hydrated film were made by removing films at regular time intervals, blotting between filter paper to remove excess liquid, and re-weighing.

\section{Microscopy}

The morphology of the composite films was examined using a JEOL 7500FA scanning electron microscope (SEM). The samples were prepared for imaging by drying in a $60{ }^{\circ} \mathrm{C}$ vacuum oven, with representative sections cut from the sample and mounted onto brass stubs using conductive tape. Some samples were coated with a nanometre thick gold layer prior to imaging to prevent charge accumulation.

\section{Spectroscopy}

Raman spectra of the starting materials (graphite, GO and CCG) and dried GG-CCG films were obtained using a Jobin Yvon Horiba HR800 Raman spectrometer. The spectra were measured between 500 and $3000 \mathrm{~cm}^{-1}$ using a $638.5 \mathrm{~nm}$ laser source with a 950-line diffraction grating. 


\section{Electrical characterisation}

The electrical resistance of dried and hydrated films were evaluated using a two-point probe method. Films were mounted on a glass slide and contacted with high purity silver paint (SPI) and two copper tape $(3 \mathrm{M})$ contacts. The current-voltage $(\mathrm{I}-\mathrm{V})$ characteristics of the films (channel length $0.1 \mathrm{~cm}$, temperature $21^{\circ} \mathrm{C}, 45 \% \mathrm{RH}$ ) were measured by applying a sawtooth DC potential (1 - $10 \mathrm{~V}$ amplitude, $100 \mathrm{mHz}$ frequency) from an Agilent waveform generator (33220A), and measuring the current flow through the circuit via an Agilent multimeter (34410A).

\section{Tensile testing}

Mechanical testing of films in the dry and hydrogel state was performed on a Shimadzu Universal Testing Machine (EZ-S) interfaced to TrapeziumX software. Sections of films (30 $\mathrm{mm}$ gauge, $10 \mathrm{~mm}$ width) were clamped between sample jaws, and a tensile load (through a $50 \mathrm{~N}$ load cell) was progressively applied to the sample to induce a strain at a rate of 0.5 $\mathrm{mm} / \mathrm{min}$ until failure. Measurements were conducted in triplicate for each sample composition.

\section{Statistical treatment}

The data was Q-tested (confidence interval $\geq 95 \%$ ) and the reported values and numerical errors are averages of the values obtained and \pm 1 standard deviation, respectively.

\section{Results and Discussion}

\subsection{Dispersion stability}


Raman spectroscopy is a widely used method for the characterisation (and identification) of carbon materials such as graphite and its conversion via exfoliation to GO and reduction to graphene ${ }^{[43,44,45,46]}$. The Raman spectrum from graphite showed the characteristic dominant G $1580 \mathrm{~cm}^{-1}$ and a smaller (lower intensity) D band around $1325 \mathrm{~cm}^{-1}$, in agreement with previous reports ${ }^{[46]}$ (results not shown). The D and G bands are indicative of the graphite edges and graphite lattice, respectively. In other words the D band (also termed the disorder band) represents $\mathrm{sp}^{3}$ bonded carbon, whereas the $\mathrm{G}$ band represents $\mathrm{sp}^{2}$ bonded carbon. It is well-known that the ratio of the intensity of these bands $\left(\mathrm{I}_{\mathrm{D}} / \mathrm{I}_{\mathrm{G}}\right)$ undergoes significant changes upon exfoliation to $\mathrm{GO}$ and reduction to $\mathrm{CCG}$. This ratio changed from $\mathrm{I}_{\mathrm{D}} / \mathrm{I}_{\mathrm{G}}=0.2$ for graphite to close to $\mathrm{I}_{\mathrm{D}} / \mathrm{I}_{\mathrm{G}}=0.90$ for $\mathrm{GO}$ after exfoliation. As expected the $\mathrm{I}_{\mathrm{D}} / \mathrm{I}_{\mathrm{G}}$ ratio exhibited an increase to 1.5 after the reduction to CCG. Our results are consistent with those presented in the literature ${ }^{[45]}$, thereby confirming that our synthesis method results in the formation of CCG.

Gellan gum - graphene dispersions were prepared by mixing gellan gum solutions with graphene dispersions (Fig. 1a). Optical microscopy images of the dispersions indicated no considerable aggregation or complexation (Fig. 1b). The dispersions were found to be stable for many weeks.

As prepared, the stock graphene dispersion exhibits a $\mathrm{pH}$ of approximately 10.5, in which carboxylic functionalities on the sheets (remaining from the reduction process) are significantly ionised. Upon mixing with gellan gum, the resultant dispersion $\mathrm{pH}$ is shifted to around 9. It has also been well demonstrated in many colloid experiments that the stability of an electrostatically stabilised dispersion is strongly dependent upon $\mathrm{pH}^{[47]}$. Fig. 2a displays the zeta potential measurement of CCG dispersions as a function of $\mathrm{pH}$ (from $\sim 10.5$ to $~$ 5.8). It was confirmed that the stability of the graphene dispersion rapidly decreases upon $\mathrm{pH}$ 
reduction, with zeta potential values approaching only incipient stability at around $\mathrm{pH} 7$. These measurements confirm that upon mixing, both GG and CCG remain within their stable $\mathrm{pH}$ range leading to the observed dispersion stability.

Our attempts to form GG-CCG hydrogels by the standard approach ${ }^{[29]}$ of addition of calcium ions to gellan-graphene dispersions resulted in immediate agglomeration. Optical microscopy of a cross-section from these hydrogels (Fig. 1c) revealed a non-uniform dispersion of the gelled sample, indicating that significant aggregation had occurred. It is well known that changes in the ionic strength can considerably modify the stability of colloidal dispersions [48]

Fig. 2b shows that addition of $\mathrm{Ca}^{2+}$ ions destabilises the colloidal $\mathrm{CCG}$ dispersion at a concentration of greater than $5 \mathrm{mM}$. This suggests that the formation of a $\mathrm{Ca}^{2+}$ cross-linked hydrogel via the standard approach may not be possible without aggregation of the graphene dispersion. This destabilisation can be explained by considering that upon addition of the divalent cations, a rapid decrease in charge density surrounding the graphene sheets occurs through shielding. As a consequence, neighbouring sheets are capable of coming into closer proximity with each other, at which point van der Waals interactions dominate, resulting in irreversible aggregation. An alternative method for the preparation of $\mathrm{Ca}^{2+}$ cross-linked hydrogels is discussed in section 3.3.

\subsection{Free-standing films}

Gellan-graphene drop-cast films were prepared from a range of dispersions by combining GG solutions with CCG dispersions. Upon removal of solvent over a 24 hour period, the dispersions formed a film layer which could be peeled from the substrate (Fig. 1d-e). 
Scanning electron microscopy (SEM) was used to investigate the surface morphology of these films (Fig. 3). It is clear that the morphology changes with increasing graphene loading (Fig. 3a-b). The graphene sheets are almost completely covered by the biopolymer at the lower loading fractions, but are clearly visible in film with loading fraction 0.047 (Fig. 3b). SEM imaging suggested that lateral dimensions of the graphene sheets in the films are on the order of a few hundred nm, similar to those reported for CCG sheets prepared using the same method of production ${ }^{[49]}$.

All films exhibited linear current-voltage characteristics indicative of Ohmic behaviour (Fig. 4a). The conductivity of the GG-CCG films with the highest loading fraction ( 0.31 by mass) was $3 \pm 1 \mathrm{~S} / \mathrm{m}$, which is higher than the values reported for polyethylene composites ${ }^{[50]}$, but significantly lower than those reported for polypyrrole composites ${ }^{[1]}$.

The electrical characteristics of the films (Fig. 4b) were analysed using the statistical percolation model ${ }^{[51]}$ which revealed a percolation threshold of $0.057 \pm 0.04$ by volume $(0.093 \pm 0.006$ by mass). The percolation threshold is significantly higher than the recently reported value ( 0.018 by volume) for films prepared using the same matrix (gellan gum) but a different conducting filler (multi-walled carbon nanotubes, MWNT) ${ }^{[40]}$. This difference in the percolation threshold between MWNT and CCG is consistent with recent work on polyethylene composites, which attributed the higher threshold for CCG to its lower aspect ratio, higher propensity to aggregate and lower ability to interlace into a network structure ${ }^{[50]}$.

Tensile testing revealed addition of CCG had a detrimental effect on the mechanical characteristics for volume loading fractions above 0.05 . Below these fractions, the stiffness (Young's modulus) of GG-CCG films was found to linearly increase with increasing CCG 
concentration. For example, the Young's modulus of GG films increased from $1.35 \pm 0.31$ GPa to $2.14 \pm 0.20 \mathrm{GPa}$ and $2.39 \pm 0.12 \mathrm{GPa}$ for films with CCG volume fractions of 0.0283 and 0.043 , respectively (Fig. 5a). The tensile strength was found to initially increase, but then decrease at the higher loading fractions. Extensibility decreased from $9.6 \pm 0.4 \%$ for the GG films to $5.7 \pm 1.3 \%$ for films with CCG volume fraction 0.043 . The interaction between the biopolymer and CCG was established by investigating the Young's modulus (E) as a function of the CCG volume fraction $\left(\mathrm{dE} / \mathrm{dV}_{\mathrm{f}}\right)$. The initial increase in the modulus provided an estimate of the GG-CCG $\mathrm{dE} / \mathrm{dV}_{\mathrm{f}}$ of $25 \pm 3 \mathrm{GPa}$, which could indicate there is some interaction between the biopolymer matrix and the filler. The $\mathrm{dE} / \mathrm{dV}_{\mathrm{f}}$ value is similar to that observed for the GG-MWNT, i.e. $\mathrm{dE} / \mathrm{dV}_{\mathrm{f}}=32 \pm 3 \mathrm{GPa}^{[40]}$.

\subsection{Hydrogel films}

In section 3.1 we showed that preparation of GG-CCG hydrogels cross-linked with $\mathrm{Ca}^{2+}$ via the standard approach ${ }^{[29]}$ failed due to a $\mathrm{Ca}^{2+}$ induced destabilisation of graphene. An alternative method was devised to form $\mathrm{Ca}^{2+}$ cross-linked hydrogels. This was achieved by using free-standing films prepared by evaporative casting of gellan gum and composite dispersions, which were then subjected to a further hydration-cross-linking step (by immersion in $\mathrm{CaCl}_{2}$ baths for up to 3 hours) to enable the formation of a $\mathrm{Ca}^{2+}$ cross-linked hydrogel film. Fig. 6a shows that the water content (WC) of GG-CCG films rapidly increases in the first 10 min and reaches a plateau value after about 20 min. The plateau WC values for films immersed in $0.1 \mathrm{M}$ and $0.5 \mathrm{M} \mathrm{CaCl}_{2}$ solutions are $48 \pm 3 \%$ and $37 \pm 1 \%$, respectively. Similar results were obtained for gellan gum hydrogel films. It is well-known that increasing the concentration of the cross-linker results in stronger binding between the GG chains in the polymer network ${ }^{[29]}$. Stronger binding could reduce the ability to take up water as evident 
from the lower WC value for films immersed in the based with the higher cross-linking concentration.

The current-voltage characteristics of gels prepared by hydrating in $0.5 \mathrm{M} \mathrm{CaCl}_{2}$ resulted in an electrical resistance of $6.3 \pm 1.0 \mathrm{k} \Omega$ (Fig. 4c). In contrast, the resistance value exhibited by films hydrated in purified water containing few ions (Milli-Q water, resistivity $18.2 \mathrm{M} \Omega \mathrm{cm}$ ) is $25 \pm 2 \mathrm{k} \Omega$ (Fig. 4c). Both these resistance values are a significant improvement on the resistance value (60 M $\Omega$ ) exhibited by the as-prepared GG-CCG films, i.e. prior to hydration. These results are consistent with previous research, which suggested that the reduced resistance of hydrated gellan gum containing films can be contributed to an ionic contribution to the current by the cation charge carriers ${ }^{[34]}$.

Tensile testing of the GG-CCG hydrogel films revealed that the values of the mechanical properties were an order of magnitude lower compared to the dry films and were dependent on the water content. For example, the Young's modulus decreased from $185 \pm 46 \mathrm{MPa}$ to $128 \pm 38 \mathrm{MPa}$ with an increase in water content from $37 \%$ to $48 \%$, see Fig. $5 \mathrm{~b}$. The tensile strength decreased from $8.7 \pm 2.6 \mathrm{MPa}$ to $6.9 \pm 2.5$, while the ductility increased from $7.2 \pm$ $0.8 \%$ to $9.4 \pm 0.7 \%$. These values are higher than the corresponding values for the GG hydrogel films of similar water content, see table 1 . Hence, the presence of graphene in these hydrogels results in a modest reinforcement effects, i.e. $32 \%$ in Young's modulus at WC $=$ $37 \%$ and $57 \%$ in tensile strength at $\mathrm{WC}=48 \%$. The observed decrease in stiffness coupled with an increase in ductility is the expected behaviour for hydrogels with increasing water content.

Table 1. Summary of mechanical properties of GG and GG-CCG films and their corresponding hydrogel films prepared by immersion in $\mathrm{CaCl}_{2}$ solutions. The $\mathrm{CCG}$ volume fraction in the as-prepared GG-CCG films is 0.0283. E, TS, $\gamma$, and WC indicate Young's modulus, tensile strength, ductility and water content, respectively. 


\begin{tabular}{|l|l|l|l|l|}
\hline Film & WC (\%) & E (MPa) & TS (MPa) & $\gamma(\mathbf{\%})$ \\
\hline GG & 37 & $140 \pm 16$ & $7.8 \pm 2.5$ & $8.8 \pm 1.8$ \\
\hline GG-CCG & 37 & $185 \pm 46$ & $8.7 \pm 2.6$ & $7.2 \pm 0.8$ \\
\hline GG & 48 & $110 \pm 13$ & $4.4 \pm 2.4$ & $14 \pm 1$ \\
\hline GG-CCG & 48 & $128 \pm 38$ & $6.9 \pm 2.5$ & $9.4 \pm 0.7$ \\
\hline
\end{tabular}

\section{Conclusions}

The preparation and characterisation of graphene-containing gellan gum composite films and hydrogels is presented. It was shown that mixing of graphene dispersions with solutions of the biopolymer gellan gum enabled the preparation of composite films with high loading fraction by evaporative casting. Electrical and mechanical testing revealed that incorporation of graphene resulted in conductivity values of up to $3 \mathrm{~S} / \mathrm{m}$ and mechanical reinforcement.

Initial attempts to produce hydrogels through conventional cross-linking were unsuccessful due to $\mathrm{Ca}^{2+}$ induced destabilisation of graphene. Instead, hydrogels with water content of $37 \%$ and $48 \%$ were prepared by a simultaneous hydration and cross-linked step by immersion of films in a calcium solution. The graphene-containing $\mathrm{Ca}^{2+}$ cross-linked gellan gum hydrogel films exhibited a modest reinforcement compared to the GG hydrogels films of similar water content and are conducting. This paper contributes to the development of graphene-containing hydrogel materials.

\section{Acknowledgements}

The authors acknowledge financial support from the University of Wollongong (UOW), the Australian Research Council (Centre of Excellence, Laureate and Future Fellowship programs) and the Australian National Fabrication Facility, and use of the facilities of the 
UOW Electron Microscopy Centre (with the assistance of Mr T. Romeo). Drs S. Gambhir, B. Muller, (both UOW), and R. Clark, P. Jackson (both CP Kelco) are thanked for assistance with preparation of graphene, electron microscopy and provision of gellan gum, respectively.

\section{References}

[1] K. S. Novoselov, A. K. Geim, S. V. Morozov, D. Jiang, Y. Zhang, S. V. Dubonos, I. V. Grigorieva, A. A. Firsov, Science 306 (2004) 666.

[2] K.S. Novoselov, D. Jiang, F. Schedin, T.J. Booth, V.V. Khotkevich, S.V. Morozov, A.K. Geim, Proc. Nat. Acad. Sci. USA 102 (2005) 10451.

[3] S. Gilje, S. Han, M. Wang, K. L. Wang, R. B. Kaner, Nano Lett. 7 (2007) 3394.

[4] C. Berger, Z. Song, X. Li, X. Wu, N. Brown, C. Naud, D. Mayou, T. Li, J. Hass, A. N. Marchenkov, E. H. Conrad, P. N. First, W. A. de Heer, Science 312 (2006) 1191.

[5] Z. Osváth, A. Darabont, P. Nemes-Incze, E. Horváth, Z. E. Horváth, L. P. Biró, Carbon 45 (2007) 3022.

[6] H.-L. Guo, X.-F. Wang, Q.-Y. Qian, F.-B. Wang, X.-H. Xia, ACS Nano 3 (2009) 2653.

[7] Y. Hernandez, V. Nicolosi, M. Lotya, F. M. Blighe, Z. Sun, S. De, I. T. McGovern, B. Holland, M. Byrne, Y. K. Gun'Ko, J. J. Boland, P. Niraj, G. Duesberg, S. Krishnamurthy, R. Goodhue, J. Hutchison, V. Scardaci, A. C. Ferrari, J. N. Coleman, Nat. Nano. 3 (2008) 563.

[8] V. C. Tung, M. J. Allen, Y. Yang, R. B. Kaner, Nat. Nano 4 (2009) 25.

[9] S. Stankovich, D. A. Dikin, G. H. B. Dommett, K. M. Kohlhaas, E. J. Zimney, E. A. Stach, R. D. Piner, S. T. Nguyen, R. S. Ruoff, Nature 442 (2006) 282.

[10] B. Jang, A. Zhamu, J. Mater. Sci. 43 (2008) 5092.

[11] F.-H. Hsu, T.-M. Wu, Synth. Met. 162 (2012) 682.

[12] Y. Xu, K. Sheng, C. Li, G. Shi, ACS Nano 4 (2010) 4324. 
[13] X. Yang, L. Qiu, C. Cheng, Y. Wu, Z.F. Ma, D. Li, Angew. Chem. Int. Ed. 50 (2011) 7325

[14] X. Yang, J. Zhu, L. Qiu, D. Li, Adv. Mater. 23 (2011) 2833.

[15] Q. Wu, Y. Sun, H. Bai, G. Shi, Phys. Chem. Phys. Chem. 13 (2011) 11193.

[16] L. Yang, J. Kong, W.A. Yee, W. Liu, S.L. Phua, C.L. Toh, S. Huang, X. Lu, Nanoscale $4(2012) 4968$.

[17] J. Chen, K. Sheng, P. Luo, C. Li, G. Shi, Adv. Mater. 24 (2012) 4569.

[18] I. Giavasis, L. M. Harvey, B. McNeil, Crit. Rev. Biotechnol. 20 (2000) 177.

[19] S. Noda, T. Funami, M. Nakauma, I. Asai, R. Takahashi, S. Al-Assaf, S. Ikeda, K. Nishinari, G. O. Phillips, Food Hydrocoll. 22 (2008) 1148.

[20] M. Tako, T. Teruya, Y. Tamaki, T. Konishi, Colloid Polym. Sci. 287 (2009) 1445.

[21] E. Miyoshi, K. Nishinari, Progr. Colloid. Polym. Sci. 114 (1999) 68.

[22] K. Nishinari, Colloid Polym. Sci. 275 (1997) 1093.

[23] S. Matsukawa, Z. Tang, T. Watanabe, Progr. Colloid. Polym. Sci. 114 (1999) 15.

[24] C. J. Ferris, M. in het Panhuis, Soft Matter 5 (2009) 3430.

[25] T. Funami, S. Noda, M. Nakauma, S. Ishihara, R. Takahashi, S. Al-Assaf, S. Ikeda, K. Nishinari, G. O. Phillips, Food Hydrocoll. 23 (2009) 548.

[26] E. Ogawa, R. Takahashi, H. Yajima, K. Nishinari, Food Hydrocoll. 20 (2006) 378.

[27] J. Horinaka, K. Kani, Y. Hori, S. Maeda, Biophys. Chem. 111 (2004) 223.

[28] K. Kani, J.-i. Horinaka, S. Maeda, Carbohyd. Polym. 61 (2005) 168.

[29] E. R. Morris, K. Nishinari, and M. Rinaudo, Food Hydrocoll. 28 (2012) 373.

[30] E. Miyoshi, T. Takaya, K. Nishinari, Food Hydrocoll. 8 (1994) 529.

[31] I. Giavasis, L. M. Harvey, B. McNeil, Crit. Rev. Biotechnol. 20 (2000) 177.

[32] A. M. Fialho, L. M. Moreira, A. T. Granja, A. O. Popescu, K. Hoffmann, I. Sá-Correia, Appl. Microbiol. Biotechnol. 79 (2008) 889. 
[33] M. S. Tapia, M. A. Rojas-Graü, A. Carmona, F. J. Rodríguez, R. Soliva-Fortuny, O. Martin-Belloso, Food Hydrocoll. 22 (2008) 1493.

[34] C. J. Ferris, M. in het Panhuis, Soft Matter 5 (2009) 1466.

[35] N. Songmee, P. Singjai, M. in het Panhuis, Nanoscale 2 (2010) 1740.

[36] L. Lu, W. Chen, ACS Nano 4 (2010) 1042.

[37] J. P. Ferrance, A. R. Juriani, J. W. Pettit, K. E. Meissner, J. Nanoelectron. Optoelectron. $6(2011) 102$.

[38] J. Boge, L. J. Sweetman, M. in het Panhuis, S. F. Ralph, J. Mater. Chem. 19 (2009) 9131.

[39] M. in het Panhuis, A. Heurtematte, W. R. Small, V. N. Paunov, Soft Matter 3 (2007) 840.

[40] G. C. Pidcock, M. in het Panhuis, Adv. Funct. Mater. 22 (2012), 4790.

[41] N. I. Kovtyukhova, P. J. Ollivier, B. R. Martin, T. E. Mallouk, S. A. Chizhik, E. V. Buzaneva, A. D. Gorchinskiy, Chem. Mater. 11 (1999), 771.

[42] W. S. Hummers, R. E. Offeman, J. Am. Chem. Soc. (1958), 80, 1339.

[43] A.C. Ferrari, Solid State Communications (2007), 143, 47.

[44] K.N. Kudin, B. Ozbas, H.C. Schniepp, R.K. Prud'homme, I.A. Aksay, R. Car, Nano Lett. (2008), 8, 36.

[45] Y. Zhou, Q. Bao, L.A.L. Tang, Y. Zhong, K.P. Loh, Chem. Mater. (2009), 21, 2950.

[46] B. Eren, D. Hug, L. Marot, R. Pawlak, M. Kisiel, R.Steiner, D.M. Zumbuhl, E. Meyer, Beilstein J. Nanotech. (2012), 3, 852.

[47] D. H. Everett, Basic Principles of Colloid Science, The Royal Society of Chemistry, London 1988.

[48] W. Norde, Colloids and interfaces in life sciences, CRC Press, New York 2003.

[49] D. Li, M. Muller, S. Gilje, R. Kaner, G. Wallace, Nat. Nano 3 (2008) 101. 
[50] J. Du, L. Zhao, Y. Zeng, L. Zhang, F. Li, P. Liu, C. Liu, Carbon 49 (2011) 1094.

[51] D. Stauffer, A. Aharony, Introduction to percolation theory, CRC Press, Florence, KY, 1994.

\section{Figures}

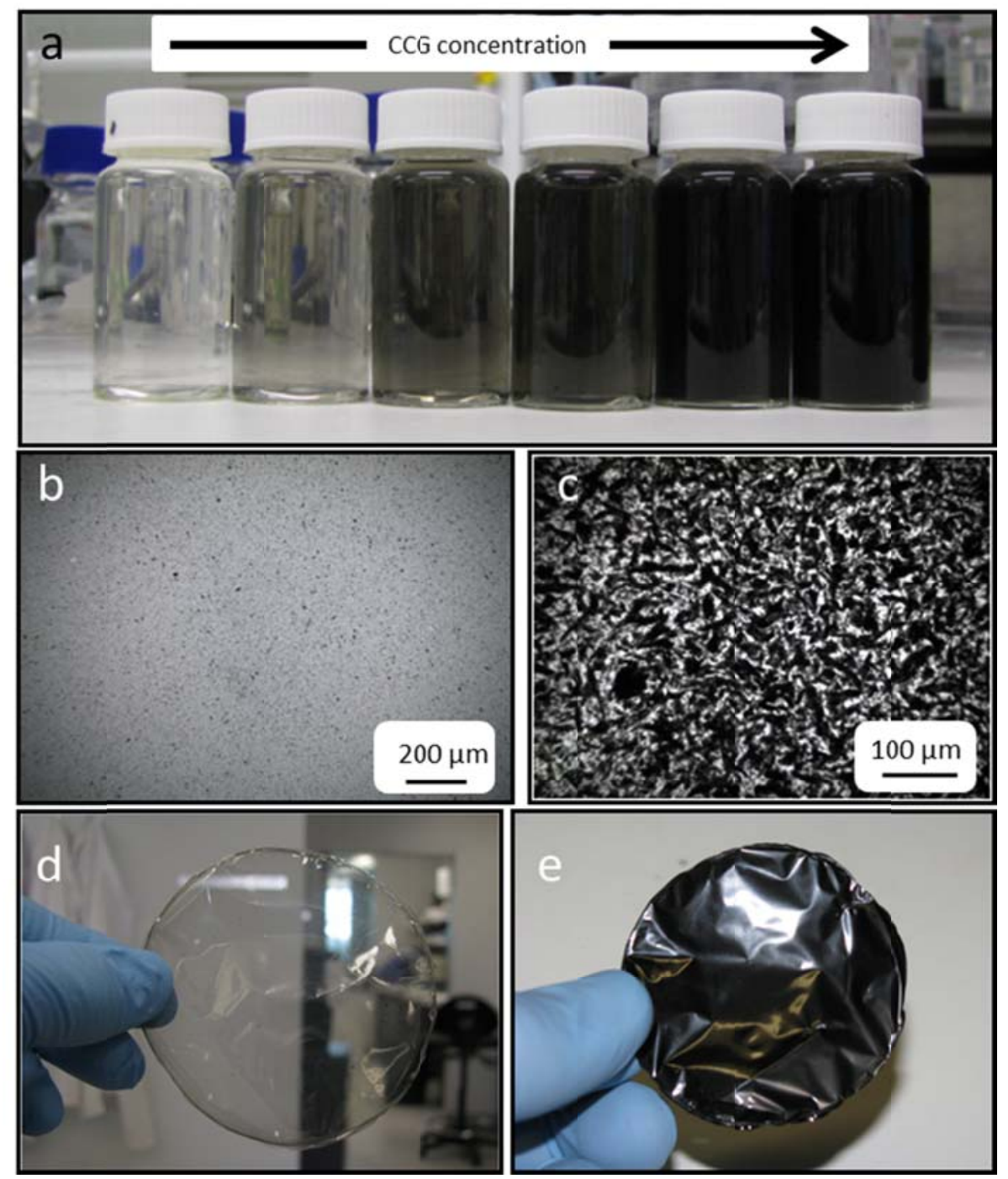

Fig. 1. (a) Photograph of typical GG-CCG dispersions with CCG concentration up to 0.45 $\mathrm{g} / \mathrm{ml}$, (b) optical microscope image of a typical stable GG-CCG dispersion. (c) Optical microscope image of the cross-section of a typical GG-CCG hydrogel cross-linked with 10 
$\mathrm{mM} \mathrm{Ca}{ }^{2+}$. (d-e) Photographs of typical free-standing GG-CCG films with CCG mass fractions of 0.0025 and 0.047 , respectively.

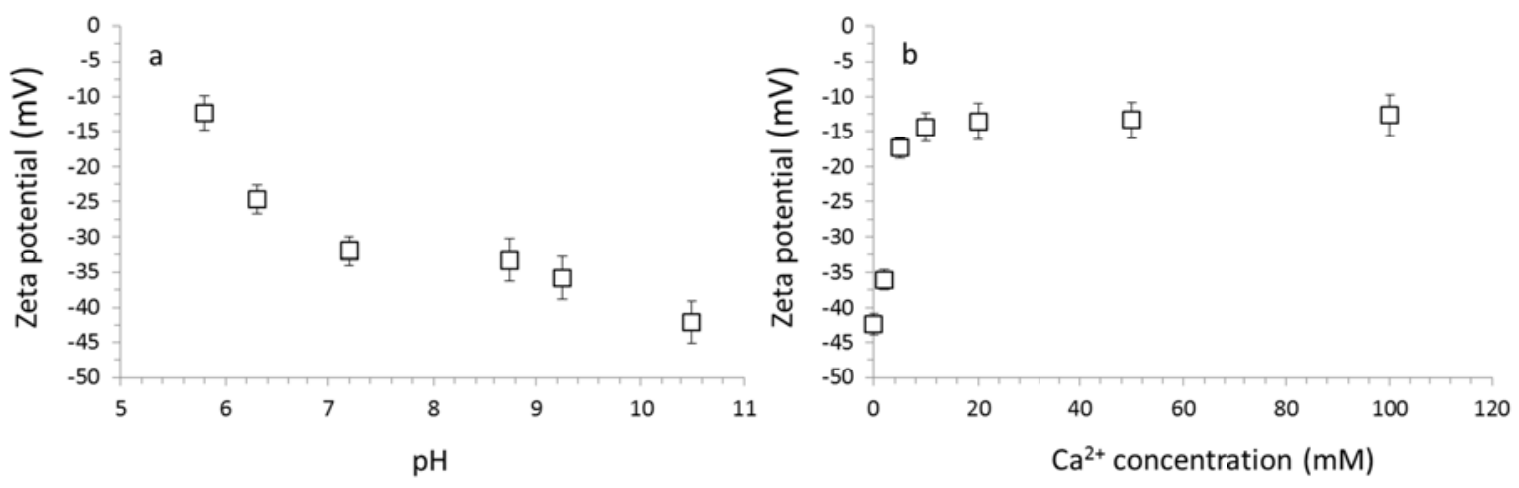

Fig. 2. Zeta potential measurement as a function of (a) $\mathrm{pH}$ change and (b) $\mathrm{Ca}^{2+}$ addition for typical CCG dispersions $(0.05 \% \mathrm{w} / \mathrm{v})$.

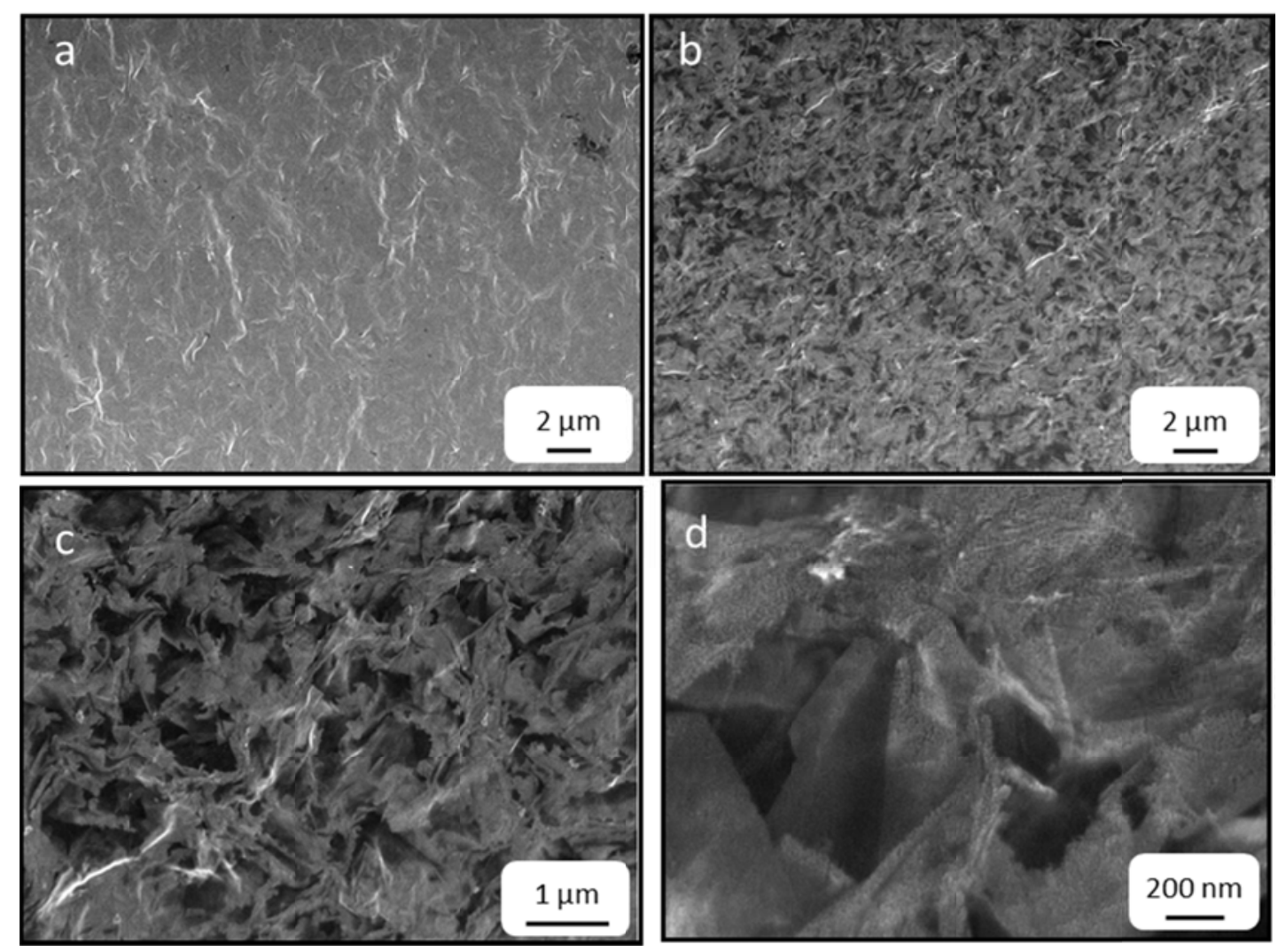


Fig. 3. (a) and (b) scanning electron microscopy (SEM) images of a typical composite film with CCG mass fraction of 0.0025 and 0.047 , respectively. (c-d) enlarged view of (b).
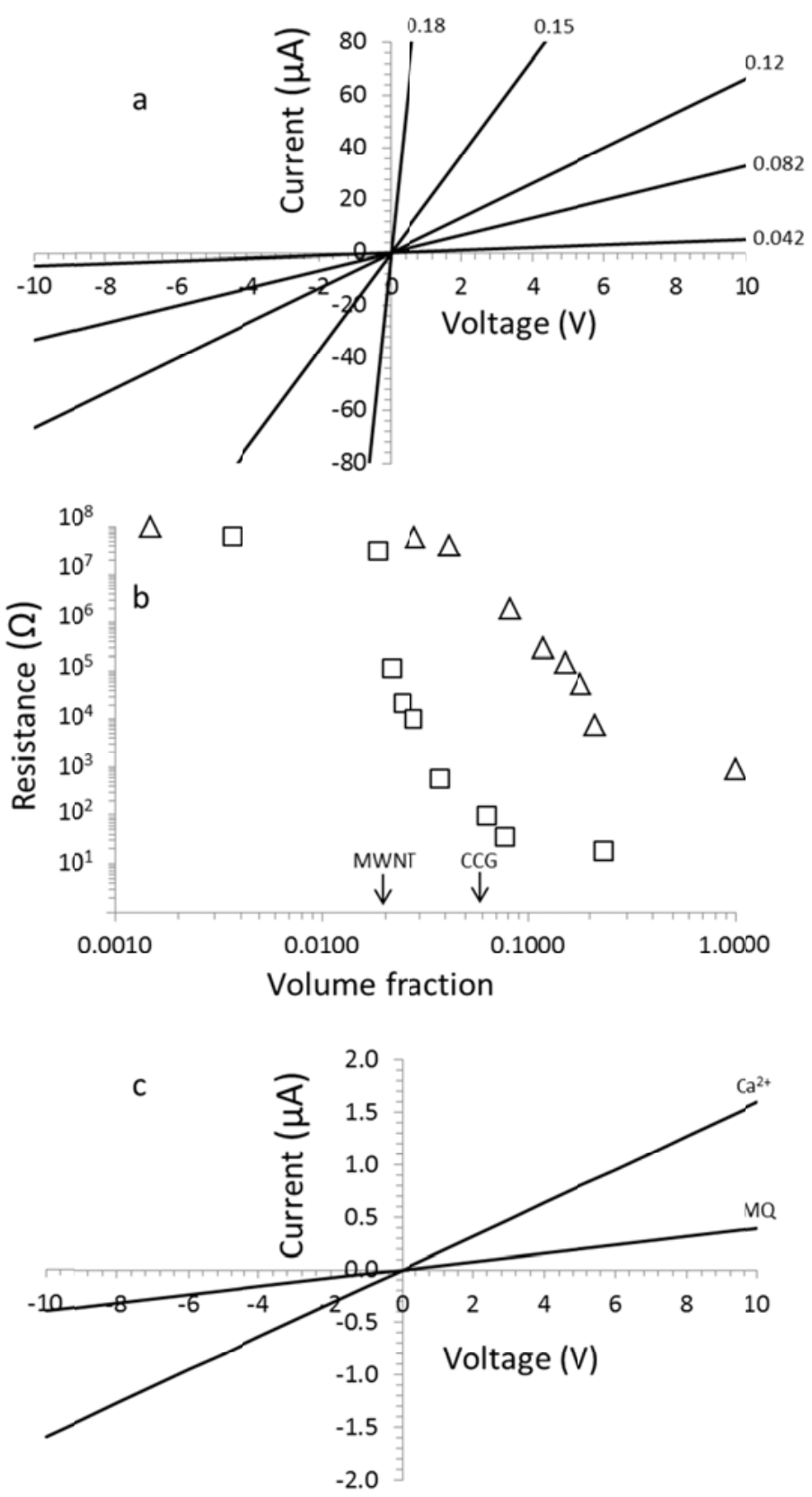

Fig. 4. (a) Current-voltage characteristics of typical free-standing GG-CCG films. Numbers indicate the CCG volume loading fraction. (b) Resistance as a function of volume fraction in GG composite films with CCG (triangles) and multi-walled carbon nanotubes (squares, data adapted from reference 40). The arrows indicate the percolation thresholds threshold obtained 
using the statistical percolation model. (c) Current-voltage characteristics of typical GG-CCG hydrogel films. $\mathrm{Ca}^{2+}$ and MQ indicate hydrogel films prepared by immersion of GG-CCG films in $\mathrm{Ca}^{2+}$ solution and Milli-Q water, respectively. Temperature, channel length and cross-sectional areas of CCG and MWNT films were approximately $21^{\circ} \mathrm{C}, 0.1 \mathrm{~cm}$ and $4.3 \mathrm{x}$ $10^{-4} \mathrm{~cm}^{2}$
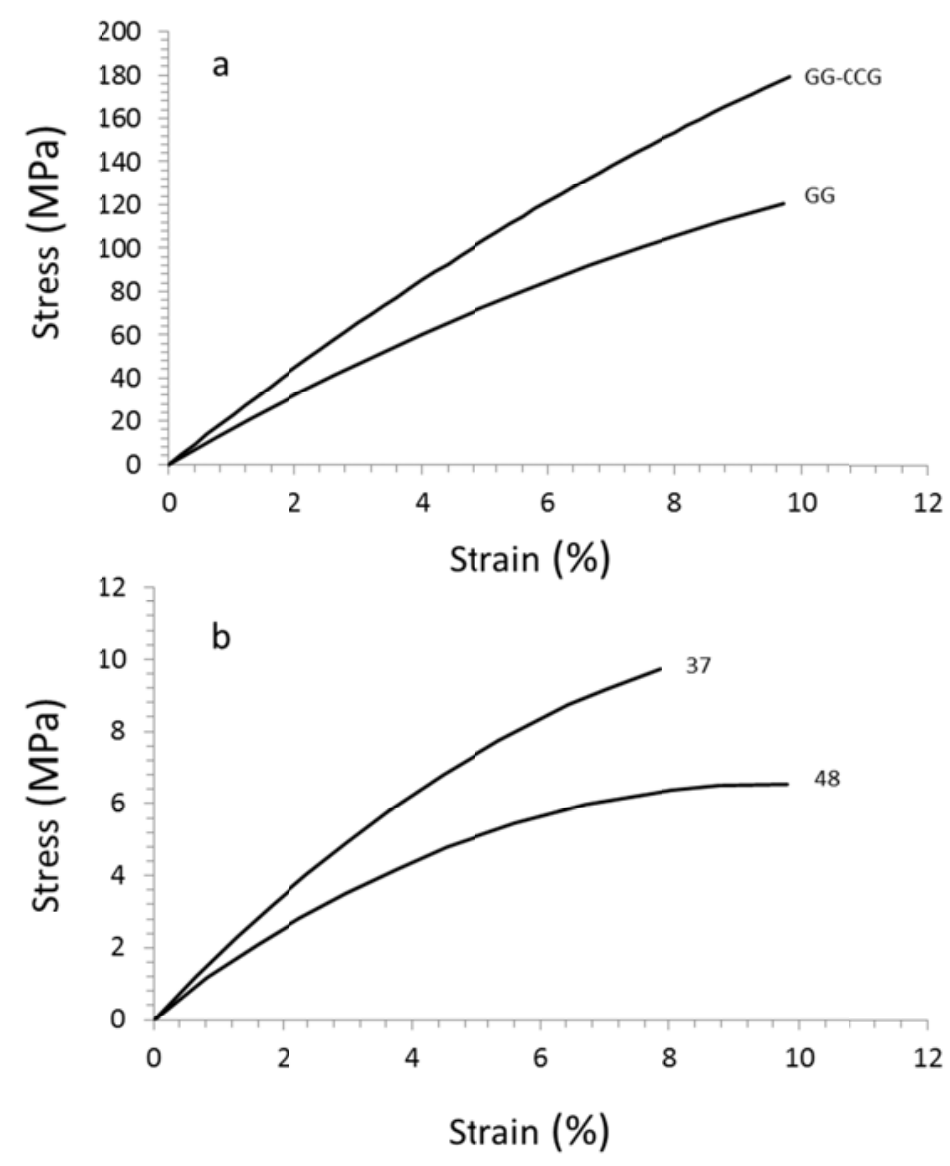

Fig. 5. Typical tensile stress-strain curves for (a) as-prepared GG and GG-CCG (volume loading fraction 0.0283 ) and (b) GG-CCG hydrogel films at water content of $37 \%$ and $48 \%$. Numbers indicate the water content. 


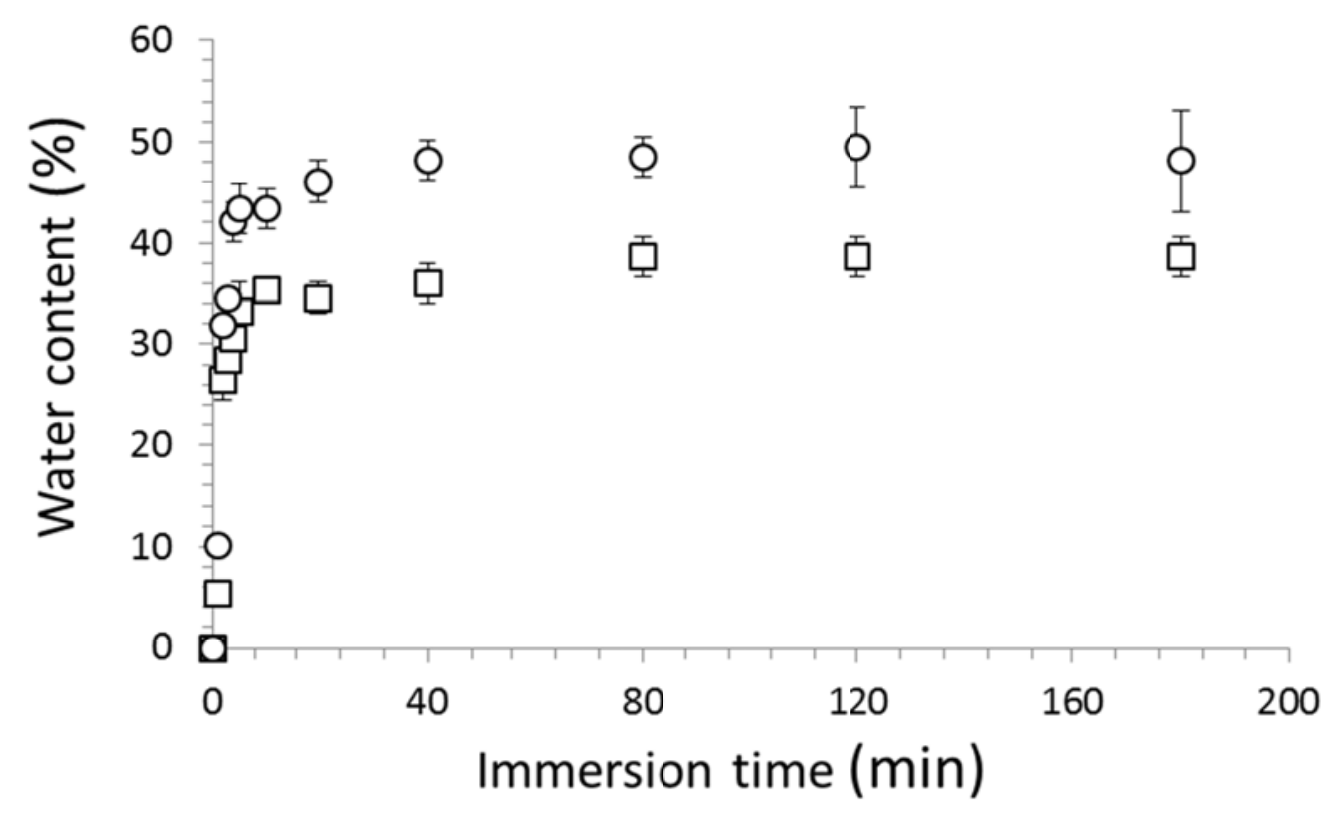

Fig. 6. Swelling behaviour of typical GG-CCG films (dry volume loading fraction of 0.0283 ) immersed in $100 \mathrm{mM}$ (circles) and $500 \mathrm{mM}$ (squares) $\mathrm{CaCl}_{2}$ solutions. 